\title{
Quality of Care Delivered to Tuberculosis Patients among Public Hospitals in Central Northeast Ethiopia
}

\author{
Balkew Asegidew Tegegn ${ }^{1}$, Betregiorgis Zegeye Hailu, Birhanu Damtew \\ Tsegaye $^{1}$, Gashaw Garedew Woldeamanuel ${ }^{3}$, Wassie Negash ${ }^{4}$
}

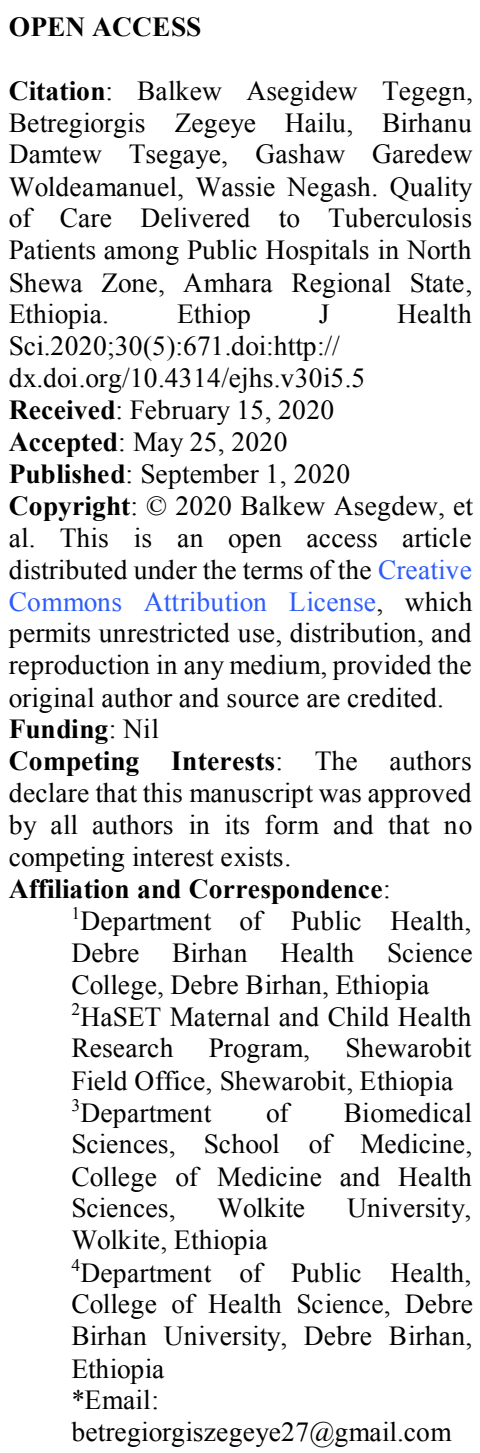

\begin{abstract}
BACKGROUND: Inappropriate Tuberculosis (TB) diagnosis and treatment contributes to unfavorable health outcome among $T B$ patients. Improving quality of healthcare service helps to avert TB related morbidity. Despite these facts, the level of quality of service is not known in the hospitals. Hence, the present study was conducted to assess the quality of care delivered to TB patients among public hospitals.

METHODS: A facility-based cross-sectional study was conducted from March 15 to April 30, 2019 in North Shewa Zone, Amhara region, Ethiopia. All TB patients who had follow-up in the hospitals were included. This resulted in the involvement of $82 \mathrm{~TB}$ patients. Data was collected by trained data collectors using facility audit, clinical observation checklists, structured questionnaire and in-depth interview. Data was analyzed using SPSS version 20. Binary logistic regression analysis was done to identify the predictors of patients' satisfaction.

RESULTS: In this study, 82 respondents with a mean age of 36.48 $( \pm 13.27)$ years were participated. The mean quality score for structural dimension was $59.5 \%$, and $53.7 \%$ of participants were found to be satisfied in outcome dimension. The mean score for process dimension of quality of service were 67.9\%. Having TB symptoms were significantly associated with the level of patient satisfaction towards $T B$ care $[A O R=0.217, p=0.015]$.

CONCLUSION:Quality of TB services from structural and outcome dimension were low and higher in process dimension. Thus, careful attention on the quality of services will help to reduce the burden of TB.

KEYWORDS: Quality, TB Care, Ethiopia

\section{INTRODUCTION}

Approximately, 95\% of all tuberculosis (TB) cases and 99\% of deaths occur in developing countries, with the greatest burden in sub-Saharan Africa and South East Asia $(1,2)$. In the middle-income countries, TB has declined relatively rapidly and has begun to loss its status as major public health problem. However, the decline is slow and tuberculosis remains a major public health problem in other developing countries.
\end{abstract}


In these countries, there is a higher frequency of patients with drug resistance TB than in other countries because of a combination of the poor quality of TB care and inappropriate use of anti TB drugs (3). Ethiopia is one of the 27 countries with high multi-drug resistant tuberculosis (MDR-TB) burden. Even if MDR-TB is highly prevalent in retreated TB cases, the prevalence of MDR-TB in newly diagnosed TB patients has been reported to be $2.8 \%$ (4).

Literature suggests that poor quality of TB care may result from discrepancies in documentation such as underreporting and gaps in the continuum of care services that the patients receive. Donabedian developed the structures, process and outcomes model as a framework for assessing the quality of healthcare services. Structure consists of physical health facility, medical equipment and staff characteristics. Processes of care involve interactions between users and the healthcare structures, the actual delivery, and receipt of care. Outcomes are consequences of care. Structures as well as processes may influence outcome directly or indirectly (5).

Even if the coverage of direct observation treatment strategy (DOTS) is high, number of people who becomes infected and died due to TB disease is still high (6). It is necessary to view the quality of TB care being rendered to patients with respect to international standards and delivered in an accessible, timely, safe, effective, efficient, and equitable manner. The quality of health care is a public health concern in many countries, particularly in the developing world including Ethiopia $(6,7)$. The quality of service for TB care is poor and not as expected as of DOTS coverage $(8,9)$. Thus, similar studies are vital for each specific service delivery sites because poor quality service will have diverse causes and it may be organization specific.

Previous studies have identified several health service delivery factors, which have impacts on adherence such as ineffective communication, poorly supervised health staff, incapability of dealing with minor illness and reduced access to TB care units (10). However, there are no previous studies, which examined the factors contributing to poor quality of TB care in the study area. Hence, the objective of this study was to assess quality of care delivered to TB patients among public hospitals in North Shewa zone, Amhara region, Ethiopia. This study will provide important information about the possible determinants of poor quality of TB care. Thus, the result will be important for public health programmers, social workers, policy makers and relevant stakeholders to design and implement effective prevention and control strategies. In particular, it will be important to improve the quality of care delivered to TB patients in the study area.

\section{MATERIALS AND METHODS}

Study design and setting:A facility-based crosssectional study was conducted from March 15 to April 30, 2019 in public hospitals of North Shewa Zone, Amhara regional state, Ethiopia. North Shewazone has one referral hospital and eight district hospitals that provide treatment for TB patients. These hospitals provide services for about 2,412,308 individuals.

Study population and eligibility criteria:The source population was all TB patients who were getting TB treatment in public hospitals of North Shewa zone and those TB patients who were getting TB treatment in the selected public hospitals of North Shewa zone. All TB patients who were getting TB treatment during the study period were included in the study. However, TB patients who were unable to provide information due to serous medical illness were excluded from the study.

Sample size determination and sampling procedure: Sample size was determined using single population proportion formula by taking the proportion of level of patient satisfaction $(\mathrm{P})$ as 0.75 from a study conducted in Addis Ababa (11) and with the assumption of $95 \%$ confidence interval and $5 \%$ margin of error. The source population was less than 10,000 (110 TB patients were obtaining TB treatment in the nine hospitals of North Shewa zone at a time of our desk review). Thus, we have used a correction formula and the final sample size was estimated to be 80 . However, the total number of TB patients receiving treatment in the nine public hospitals during the study period was 82 and all of them were included in the study.

During our desk review with TB focal persons in all the nine hospitals of North Shewazone, we realized that the number of TB patients attending these hospitals were not enough to be sampled using proportional allocation. Therefore, all hospitals with their TB patients were included in the study. Moreover, key informants who were working in the 
hospitals as a TB focal persons were selected purposively.

Level of patient satisfaction was a dependent variable while socio-demographic factors (sex, age, educational status, marital status, income), health service related variables (treatment phase, type of $\mathrm{TB}$, presence of TB symptom, duration of treatment) and others were independent variables.

The following operational deintions are used.

Quality of TB care was measured according to Donabedian quality measurement model (the result of the three dimensions i.e structural, process and the outcome dimensions).

Structural dimension was measured depending on the level of implementation of the WHOrecommended structural inputs by health facilities and the district TB control program. Fourteen 'yes/no' questions were used to assess structural dimension. Then, percentage score was calculated and structural quality was classified as: very good (90-100), good (80-89), marginal (70-79), poor (60$69)$ and very poor (50-59) (2).

Process dimension was measured through performance of the health professionals who worked at TB clinic (2). Using observation clinical checklist, the process dimension of the hospitals was investigated.We have used nine indicators (yes/no question) to assess process dimension.

Patient satisfaction was measured by using composite variable and mean score of five Likert scale questions reported the result. Thus, $\geq 75 \%$ overall satisfaction was considered as good satisfaction and $<75 \%$ was considered as poor satisfaction (2).

Data collection methods and tools: Different data collection methods and tools were used. Facility audit about the setting, availability of equipment, drugs, supplies, guidelines and trained personnel at the time of survey was conducted. Trained data collectors (clinical nurses) were deployed to assess the structural dimension and to collect information about process indicators using facility audit and clinical observation checklists, respectively. To assess the process dimension of quality of TB care, one TB focal person from each hospital was interviewed about how the treatment is carried out at the time of the survey. Moreover, interviewer administered structured questionnaire was used to collect data from TB patients attending each hospital. Thus, level of patients' satisfaction and outcome dimensions of quality of TB care were assessed using standardized structured questionnaire. These instruments were developed after reviewing various guidelines, particularly the National TB guideline of Ethiopia, thoroughly.

Data quality assurance and data analysis: To ensure the data quality, a three days' training was given for data collectors and the supervisor. The questionnaire was translated into Amharic and back into English for consistency. Moreover, pre-test was conducted on $5 \%$ of the total sample. The whole data collection process was supervised to check data completeness and consistency.

Data was entered into Epi-info version 7 and exported to SPSS version 20.0 for further analysis. Descriptive statistics was computed, and the results were reported using frequencies and percentages. Moreover, binary logistic regression analysis was performed to identify the determinant factors of patient satisfaction. A p-value $<0.05$ was considered as statistically significant.

Ethics approval and consent to participate: The study was conducted after ethical letters were obtained from Ethical Review Committee (ERC) of the College of Health Sciences, DebreBirhan University, Ethiopia. Then, permission letter was taken from the zonal health bureau and each hospital'sdirector office. Data was collected after obtaining verbal informed consent from the study participants. To keep confidentiality, codes were used and unauthorized person did not have access to the data.

\section{RESULTS}

Socio-demographic characteristics:In this study, 82 respondents were participated with $100 \%$ response rate. The mean $( \pm \mathrm{SD})$ age of the participants was $36.48( \pm 13.27)$ years with an age range of 57 years. About 36(43.9\%) of the participants were in the age group of greater than 35 years. Moreover, the majority of the respondents, 49(59.8\%),were urban dwellers (Table 1).

Health service related factors: This study found that about $56(68.3 \%)$ of the participants traveled more than $2.5 \mathrm{~km}$ to reach to TB clinics. Most of the study participants, $64(78 \%)$, responded that they accessed the TB clinics easily. This study also revealed that more than two-thirds $(64.6 \%)$ of the patients were in the $2^{\text {nd }}$ month of TB treatment (Table 2). 
Vol. 30, No. 5

September 2020

Table 1: Socio-demographic characteristics of the study participants in public hospitals of North Shewazone, Amhara region, Ethiopia, $2019(\mathrm{n}=82)$.

\begin{tabular}{|c|c|c|c|}
\hline Variables & & Frequency & Percentage \\
\hline \multirow[t]{3}{*}{ Age group (years) } & $<25$ & 20 & 24.4 \\
\hline & $25-35$ & 26 & 31.7 \\
\hline & $>35$ & 36 & 43.9 \\
\hline \multirow[t]{2}{*}{ Sex } & Male & 50 & 61.0 \\
\hline & Female & 32 & 39.0 \\
\hline \multirow[t]{2}{*}{ Residence } & Urban & 49 & 59.8 \\
\hline & Rural & 33 & 40.2 \\
\hline \multirow[t]{3}{*}{ Religion } & Orthodox & 72 & 87.8 \\
\hline & Muslim & 4 & 4.9 \\
\hline & Protestant & 6 & 7.3 \\
\hline \multirow[t]{4}{*}{ Marital status } & Single & 24 & 29.3 \\
\hline & Married & 55 & 67.1 \\
\hline & Divorced & 2 & 2.4 \\
\hline & Widowed & 1 & 1.2 \\
\hline \multirow[t]{4}{*}{ Educational status } & Illiterate & 9 & 11.0 \\
\hline & Elementary & 42 & 51.2 \\
\hline & Secondary & 18 & 22.0 \\
\hline & Certificate and above & 13 & 15.9 \\
\hline \multirow[t]{6}{*}{ Occupation } & Government employee & 13 & 15.9 \\
\hline & Private worker & 21 & 25.6 \\
\hline & House wife & 12 & 14.6 \\
\hline & Merchant & 9 & 11.0 \\
\hline & Student & 8 & 9.8 \\
\hline & Others & 19 & 23.2 \\
\hline \multirow{2}{*}{$\begin{array}{l}\text { Monthly income } \\
\text { (ETB) }\end{array}$} & $<1500$ & 45 & 54.9 \\
\hline & $\geq 1500$ & 37 & 45.1 \\
\hline \multirow[t]{2}{*}{ Family Size } & $<5$ & 57 & 69.5 \\
\hline & $\geq 5$ & 25 & 30.5 \\
\hline
\end{tabular}

Note: ETB $=$ Ethiopian Birr

Table 2: Health service related characteristics of the study participants in public hospitals of North Shewazone, Amhara region, Ethiopia, $2019(\mathrm{n}=82)$.

\begin{tabular}{|c|c|c|c|}
\hline \multicolumn{2}{|l|}{ Variables } & \multirow{2}{*}{$\begin{array}{c}\text { Frequency } \\
26\end{array}$} & \multirow{2}{*}{$\begin{array}{c}\text { Percent } \\
31.7\end{array}$} \\
\hline Distance traveled to & $<2.5 \mathrm{~km}$ & & \\
\hline TB clinic & $\geq 2.5 \mathrm{~km}$ & 56 & 68.3 \\
\hline Means- & On foot & 23 & 28.0 \\
\hline of transportation & Vehicle & 59 & 72.0 \\
\hline Facility visit history & Yes & 11 & 13.4 \\
\hline for TB treatment & No & 71 & 86.6 \\
\hline Able to get $\mathrm{TB}$ clinic & Yes & 64 & 78.0 \\
\hline easily & No & 18 & 22.0 \\
\hline \multirow[t]{3}{*}{ Treatment duration } & On $1^{\text {st }}$ month & 27 & 32.9 \\
\hline & On $2^{\text {nd }}$ month & 53 & 64.6 \\
\hline & $>2$ month & 2 & 2.4 \\
\hline \multirow[t]{4}{*}{ Type of TB } & Pulmonary positive TB & 40 & 48.8 \\
\hline & Pulmonary negative TB & 12 & 14.6 \\
\hline & Extra-pulmonary TB & 29 & 35.4 \\
\hline & MDR-TB & 1 & 1.2 \\
\hline \multirow{2}{*}{ Treatment category } & New & 74 & 90.2 \\
\hline & Retreatment & 8 & 9.8 \\
\hline Presence & Yes & 34 & 41.5 \\
\hline of symptoms & No & 48 & 58.5 \\
\hline
\end{tabular}

DOI: http://dx.doi.org/10.4314/ejhs.v30i5.5 


\section{DIMENSIONS OF QUALITY OF TB CARE}

Structural dimension indicators: In this study, structural (input) dimension was assessed using standardized facility audit checklist and semi-structured interview guide. In all hospitals, there were separate rooms for TB treatment, availability of recommended anti TB drugs, treatment guidelines, AFB test and standard TB registration book. However, there was no availability of reminder notices (such as how to cover their mouth while coughing and how to use mask) in all of the health facilities. Moreover, it was found that only one of the study hospitals was being piped with clean water to TB clinic. Apparently, the average quality score was calculated for each health facility at the first step, and then, the overall quality of this component was calculated by taking the average of all health facilities. Therefore, the average quality of structural component was $59.5 \%$ (Table 3 ).

Table 3: Structural dimension of quality of TB care in public hospitals of North Shewazone, Amhara region, Ethiopia, 2019.

\begin{tabular}{|c|c|c|c|c|c|c|c|c|c|c|}
\hline Variables & $\mathrm{HF}_{1}$ & $\mathrm{HF}_{2}$ & $\mathrm{HF}_{3}$ & $\mathrm{HF}_{4}$ & $\mathrm{HF}_{5}$ & HF $_{6}$ & $\mathbf{H F}_{7}$ & $\mathrm{HF}_{8}$ & $\mathrm{HF}_{9}$ & Total \\
\hline Separate TB room & Yes & Yes & Yes & Yes & Yes & Yes & Yes & Yes & Yes & 9 \\
\hline Trained TB care provider & Yes & Yes & Yes & Yes & Yes & Yes & Yes & Yes & Yes & 9 \\
\hline Standard/Rx guidelines & No & Yes & Yes & No & No & Yes & Yes & No & No & 4 \\
\hline $\mathrm{TB}$ poster at $\mathrm{TB}$ room & Yes & No & No & No & No & No & No & No & Yes & 2 \\
\hline All anti-TB drugs & Yes & Yes & Yes & Yes & Yes & Yes & Yes & Yes & Yes & 9 \\
\hline $\begin{array}{l}\text { Reminder notices for specific } \\
\text { interventions }\end{array}$ & No & No & No & No & No & No & No & No & No & 0 \\
\hline $\begin{array}{l}\text { HF is comfortable and safe for } \\
\text { TB treatment }\end{array}$ & No & Yes & Yes & Yes & Yes & Yes & Yes & Yes & Yes & 8 \\
\hline $\begin{array}{l}\text { Supervisory support in the last } 6 \\
\text { months }\end{array}$ & No & No & Yes & No & No & Yes & Yes & No & No & 3 \\
\hline Room with windows & Yes & Yes & Yes & Yes & Yes & No & Yes & Yes & Yes & 8 \\
\hline AFB test & Yes & Yes & Yes & Yes & Yes & Yes & Yes & Yes & Yes & 9 \\
\hline Clean water & No & No & No & Yes & No & No & No & No & No & 1 \\
\hline $\begin{array}{l}\text { Comfortable waiting rooms for } \\
\mathrm{HE}\end{array}$ & No & Yes & Yes & No & No & No & Yes & No & Yes & 4 \\
\hline Standard TB register & Yes & Yes & Yes & Yes & Yes & Yes & Yes & Yes & Yes & 9 \\
\hline $\mathrm{HE}$ program on $\mathrm{TB}$ & No & No & No & No & No & No & No & No & No & 0 \\
\hline Total (available) & 7 & 9 & 10 & 8 & 7 & 8 & 10 & 7 & 9 & \\
\hline Percentage & $50.0 \%$ & $64.3 \%$ & $71.4 \%$ & $57.2 \%$ & $50.0 \%$ & $57.2 \%$ & $71.4 \%$ & $50.0 \%$ & $64.3 \%$ & $59.5 \%$ \\
\hline
\end{tabular}

Note:HF = Health facility, AFB = Acid fast bacilli, HE = Health education 
The key informants' (TB focal persons') suggestion also indicated that most infrastructures, necessary materials and all anti-TB drugs were available in the majority of the health facilities. These necessary materials and all anti-TB drugs were also observed in our supervision. Moreover, all health facilities had trained health care providers. On the other hand, there were no comfortable waiting areas for health education, reminder notice for specific interventions and clean water source. One TB focal person said: "All TB patients bring water from their home to take their medication each morning during DOTs phase of treatment because there is no clean water source in our hospital".

Process dimension indicators:Using observation clinical checklist, the process dimension of the hospitals was investigated.
Accordingly, care providers of all health institutions prescribed appropriate regimens and assessed patients' adherence. Moreover, the majority of the health workers did not demonstrate greeting, respectfulness and encouraging attitude to their patients while the patients received their drugs. In contrast, patients were seen in private TB rooms and were participated in decision-making processes of service delivery (Table 4). TB focal persons' (key informants') suggestions also indicated that helath care providers have prescribed appropriate regimens and counseled the patients. However, all TB focal persons said: "There is a gap of documenting written record of medications, bacteriologic response and adverse reactions of the medications".

Table 4: Process dimensions of quality of TB care in Public hospitals of North Shewa zone, Amhara region, Ethiopia, 2019

\begin{tabular}{|c|c|c|c|}
\hline \multirow[t]{2}{*}{ Process indicators } & \multicolumn{2}{|c|}{$\begin{array}{l}\text { Performing } \\
\text { hospitals }\end{array}$} & \multirow{2}{*}{$\begin{array}{c}\text { each } \\
\%\end{array}$} \\
\hline & Yes & No & \\
\hline Care provider gave greeting for the patient & 2 & 7 & 2.8 \\
\hline Care providers prescribed appropriate regimen and assessed adherence & 9 & 0 & 100 \\
\hline Care provider gave medication counseling to the patient & 8 & 1 & 88.9 \\
\hline Patient were taking their medications by DOT program & 8 & 1 & 88.9 \\
\hline $\begin{array}{l}\text { Maintaining written record of medications, bacteriologic response and adverse } \\
\text { reactions }\end{array}$ & 0 & 9 & 0 \\
\hline Patient centered approach to administration of drug treatment & 8 & 1 & 88.9 \\
\hline Care provider gave the patient about appropriate appointment & 9 & 0 & 100 \\
\hline examination room comfortable to the patients (during examining the $\mathrm{Pt}$ ) & 9 & 0 & 100 \\
\hline Care providers demonstrated to the patient how to take medication & 2 & 7 & 2.8 \\
\hline
\end{tabular}

\section{OUTCOME DIMENSION}

Level of patient satisfaction:The overall satisfaction score for outcome dimension was $53.7 \%$. The majority of the respondents, 74(90.2\%), were satisfied with the respect offered by healthcare providers, and about $70(85 \%)$ respondents were satisfied with the adequacy and appropriateness of working hours. About 55(67\%) participants were dissatisfied about completeness of information given to the patients regarding treatment and effectiveness of the services (Table 5).

Factors associated with patient satisfaction: First, binary logistic regression analysis was done to see any crude association between the level of patient satisfaction and the various independent variables such as socio-demographic variables and health service related variables. Second, variables with $\mathrm{p}<$ 0.25 in bivariate analysis were selected and enrolled into multivariable binary logistic regression analysis. Age, sex, TB symptoms, TB treatment duration and type of TB were the candidates for multivariable analysis. After doing forward logistic regression analysis, having TB symptoms had significant association with level of patients' satisfaction towards $\mathrm{TB}$ care $[\mathrm{AOR}=0.217,95 \% \mathrm{CI}$ $=(0.064,0.743), \mathrm{p}=0.015]$. About $79.3 \%$ of the patients with TB symptoms were less satisfied than those patients who had no TB symptoms during TB treatment (Table 6). 
Table 5: Level of patient satisfaction with quality of TB care in Public hospitals of North Shewa zone, Amhara region, Ethiopia, 2019.

\begin{tabular}{llllll}
\hline & \multicolumn{3}{c}{ Level of satisfaction } & Very \\
Variables & $\begin{array}{l}\text { Very } \\
\text { Satisfied } \\
\text { n (\%) }\end{array}$ & $\begin{array}{l}\text { Satisfied } \\
\text { n(\%) }\end{array}$ & $\begin{array}{l}\text { Neutral } \\
\text { n (\%) }\end{array}$ & $\begin{array}{l}\text { Dissatisfied } \\
\text { n (\%) }\end{array}$ & $\begin{array}{l}\text { Dissatisfied } \\
\text { n (\%) }\end{array}$ \\
\hline Distance to access HF & $4(4.9 \%)$ & $66(80.5 \%)$ & $3(3.7 \%)$ & $9(11 \%)$ & 0 \\
Respect offered by HCP & $2(2.4 \%)$ & $74(90.2 \%)$ & $1(1.2 \%)$ & $5(6.1 \%)$ & 0 \\
Measures taken to assure privacy & $78(95.1 \%)$ & $3(3.7 \%)$ & $11.2 \%)$ & 0 & 0 \\
Measures to keep confidentiality & $2(2.4 \%)$ & $77(93.9 \%)$ & $3(3.7 \%)$ & 0 & 0 \\
Completeness of information given & $1(1.2 \%)$ & $55(67.1 \%)$ & $7(8.5 \%)$ & $17(20.7 \%)$ & $2(2.4 \%)$ \\
Access of HCP as the patients need & $2(2.4 \%)$ & $47(57.3 \%)$ & $2(2.4 \%)$ & $30(36.6 \%)$ & $1(1.2 \%)$ \\
Access of HCP to refill medication & $4(4.9 \%)$ & $44(53.7 \%)$ & $4(4.9 \%)$ & $29(35.4 \%)$ & $1(1.2 \%)$ \\
HCP welcoming and respect & $3(3.7 \%)$ & $63(76.8 \%)$ & $6(7.3 \%)$ & $10(12.2 \%)$ & 0 \\
Waiting time & $7(8.5 \%)$ & $69(84.1 \%)$ & $2(2.4 \%)$ & $4(4.9 \%)$ & 0 \\
Appropriateness of working hours & $5(6.1 \%)$ & $70(85.4 \%)$ & $2(2.4 \%)$ & $5(6.1 \%)$ & 0 \\
Time spent with HCP & $2(2.4 \%)$ & $69(84.1 \%)$ & $5(6.1 \%)$ & $6(7.3 \%)$ & 0 \\
Explanation to patient's question & $4(4.9 \%)$ & $68(82.9 \%)$ & $9(11 \%)$ & $1(1.2 \%)$ & 0 \\
Ability to Dx, treat and care of TB & $2(2.4 \%)$ & $78(95.1 \%)$ & $2(2.4 \%)$ & 0 & 0 \\
Appointment system of follow up & $4(4.9 \%)$ & $74(90.2 \%)$ & $3(3.7 \%)$ & $1(1.2 \%)$ & 0 \\
Check clinical condition & $1(1.2 \%)$ & $65(79.3 \%)$ & $7(8.5 \%)$ & $9(11 \%)$ & 0 \\
Uses medical terms & $3(3.7 \%)$ & $70(85.4 \%)$ & $6(7.3 \%)$ & $3(3.7 \%)$ & 0 \\
\hline
\end{tabular}

Note: $\mathrm{HF}=$ Health facility, $\mathrm{HCP}=$ Health care provider, Dx $=$ Diagnosis

Table 6: Multivariable binary logistic regression analysis of variables associated with patient satisfaction in public hospitals of North Shewa zone, Amhara region, Ethiopia, 2019.

\begin{tabular}{|c|c|c|c|c|c|}
\hline Variable & & Satisfied & Dissatisfied & COR(95\% CI) & AOR(95\% CI) \\
\hline \multirow{3}{*}{$\begin{array}{l}\text { Age } \\
\text { (years) }\end{array}$} & $<25$ & 13 & 7 & $1.327(0.427,4.118)$ & \\
\hline & $25-35$ & 10 & 16 & $0.446(0.159,1.252)^{*}$ & \\
\hline & $>35$ & 21 & 15 & 1.00 & \\
\hline \multirow{2}{*}{ Sex } & Male & 31 & 19 & 1.00 & \\
\hline & Female & 13 & 19 & $0.419(0.169,1.039)$ & \\
\hline Presence & Yes & 12 & 22 & $0.273(0.108,0.688)^{* *}$ & $0.217(0.064,0.743)^{* *}$ \\
\hline $\begin{array}{l}\text { of } \quad \text { TB } \\
\text { symptom }\end{array}$ & No & 32 & 16 & 1.00 & \\
\hline \multirow{3}{*}{$\begin{array}{l}\text { Treatment } \\
\text { duration }\end{array}$} & $1^{\text {st }}$ month & 9 & 15 & 1.00 & \\
\hline & $2^{\text {nd }}$ month & 16 & 13 & $2.051(0.680,6.186)$ & \\
\hline & $>2$ month & 19 & 10 & $3.167(1.026,9.770)$ & \\
\hline \multirow{3}{*}{$\begin{array}{l}\text { Type of } \\
\text { TB }\end{array}$} & $\begin{array}{l}\text { Pulmonary } \\
\text { smear +ve }\end{array}$ & 18 & 22 & 1.00 & \\
\hline & $\begin{array}{l}\text { Pulmonary } \\
\text { smear -ve }\end{array}$ & 6 & 6 & $1.222(0.336,4.448)$ & \\
\hline & $\begin{array}{l}\text { Extra- } \\
\text { pulmonary } \\
\text { TB }\end{array}$ & 20 & 10 & $\begin{array}{l}2.444(0.916,6.526) \\
* *\end{array}$ & \\
\hline
\end{tabular}

Note $\mathrm{COR}=$ Crude odds ratio, $\mathrm{AOR}=$ Adjusted odds ratio, ${ }^{*}=\mathrm{p}$ - value $<0.25, * *=\mathrm{p}$ - value $<0.05, * * *=\mathrm{p}$ - value $<0.001$ 


\section{DISCUSSION}

Treatment of TB is the cornerstone of any National Tuberculosis Program (NTP). Assessing the quality of TB treatment services is important, because it tells us how the health system is performing and leads to improved care. In this study, effort has been made to identify constraints in all components (structural, process and outcome) of TB care using Donabedian's quality assessment model in healthcare.

In this study, the overall quality score of structural components was $59.5 \%$, which indicates that the majority of the studied facilities were structurally poor. The structural quality score found in our study is better than a study conducted in Jimma zone with overall structural quality score of $56 \%$ (8). However, it is lower than a study conducted in Sidamazone, which reported $85 \%$ overall structural quality score (2). Thismight be due to discrepancy in the program managers' attention for the program, resource allocation and infrastructure variations.

The current study found weak supervision patterns. Only three public hospitals were supervised in the last 6 months, and the supervision pattern was also unplanned and lacked the written form of feedback.Our findings are comparable with the findings of a study conducted in Sidama zone, South Ethiopia (2). Planned supervision patterns will help to identify and fill the health facility gaps. Thus, it should be strong enough to support all facilities. From the drug and diagnostic supplies of structural quality of TB cares, all of the studied hospitals that had first line anti-TB drugs were sufficient for one month. This is consistent with the national minimum recommendation that very facility should have at least a one month stock level for existing patients.
Health education program for TB control activities was found to be poor in all health facilities, and there were no TB posters posted in visible areas. This is also comparable with a study conducted in Sidama zone and Addis Ababa, Ethiopia (2,11). This might be due to poor attention given by health care providers and program coordinators for the health education activities, even if it has a great role on prevention of TB transmission. Only one of the studied hospitals had clean water supply. This finding was in line with a study conducted in Sidama zone (2) but opposed to a study conducted in Jimma(8). This might be due to lack of resources or lack of attention for clean water supply near to TB clinic. The healthcare provider also prescribed appropriate regimen and was capable of assessing adherence. This is also in line with the study conducted inJimma and Addis Ababa $(2,11)$. This might be due to adequate access of training regarding the management of TB. This study also revealed that health care providers did not give respect to and approach the patients in a friendly manner. This finding is in line with a study conducted in Sidama (2). However, it is contrary to a study conducted in Addis Ababa (11). This might be due to difference in compassionate care between health professionals.

Patient satisfaction is an important quality outcome indicator of healthcare in the hospital settings. This study revealed that the overall level of patients satisfaction score with TB treatment services was $53.7 \%$. The level of patients' satisfaction score in this study was comparable with a study conducted in public health facilities of Bahir Dar city administration where about $53.8 \%$ of respondents were fully satisfied with their TB treatment service (13). However, the level of patients' satisfaction found in our study was lower 
than the one in a study done in Sidama zone, which was $71.6 \%$ (2). This discrepancy might be due to variations in structural and process dimensions between the studied hospitals and other hospitals. In line with a study conducted in Addis Ababa (12), binary logistic regression analysis results of our study showed that having TB symptoms hada significant association with level of patients' satisfaction with TB care.

The findings of this study indicated that there was poor overall structural dimension of quality of TB care services being rendered to patients.However, each parameter used to measure structural dimension may not have equal contribution to the quality of care. This study also found that the overall level of patient satisfaction was low towards TB care. Having TB symptoms during TB treatment was the only statistically significant and independent predictor of the level of patient satisfaction. Thus, regular and continuous health education is needed to prevent unnecessary outcomes. In addition, continuous supportive supervision is important to identify the gaps, to conduct timely intervention and give necessary training for all healthcare providers who are working in TB clinics.

\section{ACKNOWLEDGMENTS}

The authors would like to extend their deepest appreciation to staff members of all hospitals and North Shoa Zone Health Department for their cooperation and provision of the necessary information for this study. We would also like to thank all study participants for their cooperation.

\section{REFERENCES}

1. Eticha BM, Atomsa A, Tsehaineh B, Berheto TM. Patient's perspectives of the quality of tuberculosis treatment services in South Ethiopia. American Journal of Nursing 2014; 3(4):48-55.

2. Megene SL, Yesuf EA, Melese D, Babure ZK. Quality of tuberculosis treatment services in public hospitals of Sidama Zone, Southern Ethiopia. Journal of public health and epidemiology 2016; 10 (9): 332-347.

3. WHO. Global database, TB treatment outcomes. 2013. Accessed November 20, 2019.

4. Bulage L, Sekandi J, Kiganiy O, Mupere E. The quality of tuberculosis services in health care centers in a rural district in Uganda:the providers and clients perspective. Tuberculosis research and treatment 2014; 2014.

5. WHO, Global Tuberculosis Report, 2014. https:/www.who.int/tb/publications/gl obal_report/gtbr14_main_text.pdf.

Accessed on 23 November 2019

6. Cazabon D, Alsdurf H, Satyanarayana S, Nathavitharana R, Subbaraman R, Daftary A, et al. Quality of tuberculosis care in high burden countries: the urgent need to address gaps in the care cascade. Int $J$ Infect Dis 2017;56:111-6.

7. Billingsley KM, Smith N, Shirley R, Achieng L, Keiser P. A quality assessment tool for tuberculosis control activities in resource limited settings. Tuberculosis 2011;91:S49-53.

8. Geremew T, Jira C, Girma F. Assessment of quality of care delivered for infectious pulmonary tuberculosis patients in Jimma Zone, South West Ethiopia. Ethiopian Journal of Health Sciences 2011; 21: 3948. 
9. WHO. Global plan to end TB 20162020.http://www.stoptb.org/assets/doc uments/global/plan/GlobalPlanToEndTB _TheParadigmShift_20162020_StopTBPartnership.pdf. Accessed on 23 November 2019.

10. Belete G. Evaluation of Directly Observed Tuberculosis treatment strategy in Ethiopia: patient centeredness and satisfaction. 2016; http://uir.unisa.ac.za/handle/10500/22 074. Accessed on 23 November 2019.

11. Gebrekidan G, Tesfaye G, Hambisa MT, Deyessa N. Quality of tuberculosis care in private health facilities in Addis Ababa,
Ethiopia. Tuberculosis and treatment 2014; $\quad$ http://dx.doi.org/10.1155/ 2014/720432.

12. Getahun B, Nkosi ZZ. Satisfaction of patients with directly observed treatment strategy in Addis Ababa, Ethiopia: A mixed-methods study. PloS One 2017;12(2):e0171209.

13. Mulatu K, Amanu A, Alemayehu B. Assessment of the quality of directly observed treatment short-course of tuberculosis in Bahir Dar city administration, North West Ethiopia. Journal of Public Health 2015; 3(1):6-13. 